\title{
CORRESPONDENCE
}

\section{JOINTS : THEIR INITIATION AND PROPAGATION WITH RESPECT TO BEDDING}

SIR,-In a recent paper in the Geological Magazine, Hill (1966) favours the idea that joints in sedimentary rocks " may have originated at the bedding planes, coming together in the centre of the bed ". He further suggests, by analogy with fractures in glass, that joints may be initiated at imperfections on the bedding planes such as sole markings. Finally he suggests an observational check on this idea, as fractures in bedded rocks may prove to be parallel to linear structures on the bedding planes.

The idea of joints settling out from opposite sides of a bed and meeting in the middle to give a continuous planar fracture seems, on general grounds, highly improbable : and yet joints generally are planar, even when widely spaced in thick beds of sandstone or limestone. It is much easier to think of each joint as having a single point, or line of origin, from which it may spread in one or more directions.

The analogy with glass is ill-chosen, because sedimentary rocks, unlike glass, are anisotropic (Potter and Pettijohn, 1963, pp. 44-8).

Observations on sandstones and limestones indicate that bedding plane structures, far from acting as foci for the initiating of joints, have very little direct control over jointing. On the other hand the internal fabric of the rocks seems to influence both the direction and the intensity of jointing. The evidence for these views is summarized below.

Linear bedding plane structures are of two sorts, erosional and depositional, and both are usually found at interfaces between coarse and fine sediment. The erosional structures, cut in fine (cohesive) sediment, are usually found as casts on the soles of the overlying coarse beds. Familiar examples are flute casts and groove casts, and these are aligned in the current direction. Depositional structures-ripple marks-form during the transport and deposition of coarse (non-cohesive) sediment. They are usually found on the tops of the coarse beds, and are aligned at right-angles to the current direction. Current-deposited coarse sediment is anisotropic, and generally has monoclinic symmetry. The long axes of the detrital grains show a preferred orientation in the current direction, with a slight inclination upstream (imbrication). The plane of symmetry is at right-angles to the bedding and includes the current direction (Potter and Pettijohn, 1963, fig. 3, 12).

Silurian turbidites in Wales commonly have one set of joints parallel to the current direction, which is the same for erosional and depositional structures. This parallelism extends to beds without bedding plane structures. One specimen of a graded bed five inches thick with flute casts at the base, is bounded on two sides by joints parallel to the current direction and about five inches apart. Between these two joints are two smaller parallel joints which penetrate the specimen from the top downwards, but fail to reach the base ; nor is there any corresponding joint coming up from below to meet them. In these examples the parallelism between joints and linear sole markings seems to be fortuitous.

The strongest piece of evidence for the importance of depositional fabric as opposed to sole markings, in determining the orientation of joints, comes from the detailed study of a Miocene turbidite in California (Spotts and Weser, 1964). In this bed there is a consistent divergence of about 45 degrees between the direction of the erosional current, shown by the sole markings, and the depositional current, inferred from grain orientations. One of the two modal fracture directions is parallel to the modal grain orientation but there is no correlation at all between the fracture pattern and the orientation of the sole markings.

Detailed studies of the Great Scar Limestone of Yorkshire (P. S. Doughty, 1962 : Stratification and jointing in the Great Scar Limestone of North-West Yorkshire, M.Sc. Thesis, Nottingham) show a close correlation between 
lithology and the frequency of jointing. Where bedding planes mark a distinct change in lithology, the density of the jointing also changes. This change is independent of any irregularities on the bedding planes. If stress concentrations were built up at bedding planes, the density of jointing would be expected to decrease away from the bedding planes into the middle of the beds. This is not observed. In the Great Scar Limestone bedding plane partings may well result from differential expansion due to jointing in the overlying and underlying strata. Bedding plane partings are rarely developed in the absence of differences in joint density above and below.

\section{REFERENCES}

HILL, P. A., 1966. Joints : their initiation and propagation with respect to bedding. Geol. Mag., 103, 276-9.

Potter, P. E., and F. J. Petrijohn, 1963. Palaeocurrents and basin analysis, Springer-Verlag, Berlin.

SPOTTS, J. H., and O. E. WeSER, 1964. " Directional properties of a Miocene turbidite, California." In Turbidites (Ed. A. H. Bouma and A. Brouwer), pp. 199-221.

W. A. Cummins.

R. J. Firman.

Department of Geology,

THE UNIVERSITY, NotTINGHaM.

SIR,-I am grateful to Cummins and Firman for their useful and factual comments on my paper.

The idea of joints setting out from opposite sides and meeting in the middle is by itself, too simplified, suggesting a local, haphazard, and spontaneous initiation of jointing. What I wanted to suggest was that continuous joints in bedded rock were probably-because of the great lateral extent of the beds compared to their thickness - propagated laterally.

The shape (leading edge) of the advancing fracture is of course unknown. It may have been convex or concave forward with either a pointed or a rounded (as in my diagram) tip. Or it may have been convoluted depending upon the thickness, density, composition and grain size of, and the stress distribution within one particular bed from point to point.

The analogy with glass becomes ill-chosen only when blocks of glass and blocks of sedimentary rock are compared in the laboratory. When, however, sheets of glass are laid one above the other and compared with beds of sedimentary rock, the analogy becomes closer. In fact for an indoor experimental study of fracture propagation in layered rock it provides the closest analogy that I can think of. The sheets of glass may be heated or compressed to provide a joint "source" while the surfaces between the sheets can be greased or mudded or scarred or sprinkled with graphite or fine grit in an attempt to reproduce some of the structures found along bedding planes.

Whether or not bedding plane structures have "little direct control over jointing ", I do not know. More observations and more experiments are needed. It may well be that bedding plane structures do initiate joints whereas the internal fabric (i.e. preferred orientation if any) determines to a certain extent the direction of jointing.

In general the influence of the internal fabric would decrease at higher confining pressures. Thus of two sets of joints suspected in the one area to be of different ages, the set with no consistent relationship to the internal fabric would probably be the earlier, formed presumably when the rock was under higher confining pressure at greater depth.

SEDIMENTOLOGY RESEARCH LABORATORY,

Patrick Arthur Hill.

UNIVERSITY OF READING,

READING. 